\title{
The impact of TFPI on coronary atherosclerotic burden
}

\author{
Kahraman $\mathrm{S}^{1}$, Erdim $\mathrm{R}^{2}$, Helvacioglu $\mathrm{F}^{1}$, Dogan $\mathrm{A}^{1}$, Sozer $\mathrm{V}^{3}$, Gunay $\mathrm{D}^{4}$, Aytekin $\mathrm{S}^{2}$, Aytekin $\mathrm{V}^{2}$ \\ Istanbul Bilim University, Faculty of Medicine, Department of Cardiology, Istanbul, Turkey. \\ serkankahraman_86@outlook.com
}

\section{ABSTRACT}

OBJECTIVES: We aimed to associate a coronary artery disease (CAD) presence and severity with endothelial dysfunction (ED), carotid intima media thickness (CIMT) and Tissue Factor Pathway Inhibitor (TFPI).

BACKGROUND: ED has a central role in atherosclerosis. CIMT and TFPI activity are also related with atherosclerosis and CAD.

METHODS: In our prospective observational study, 50 patients had CAD and 30 had normal coronary arteries. Endothelial function was evaluated by endothelium-dependent flow-mediated dilatation (FMD) and nitroglycerinemediated dilatation (NMD) measurements. CIMT and Serum TFPI levels were also measured.

RESULTS: TFPI was a statistically significant determinant between the two groups with an increased level in CAD (+) group (84.9 \pm 19.3 vs $70.2 \pm 14.7, p=0.001)$. There was a positive correlation between CIMT and Gensini $(r=0.34, p=0.014)$. There was a strong negative correlation between Gensini and FMD-NMD, statistically significant (FMD: $r=-0.715, p<0.001$; NMD: $r=-0.718, p<0.001$ ).

CONCLUSION: We observed that ED, increased CIMT and TFPI levels were associated with CAD. Additionally, increased CIMT measurements and decreased FMD and NMD values had a positive correlation with GSS (Tab. 4, Fig. 6, Ref. 50). Text in PDF www.elis.sk.

KEY WORDS: coronary artery disease, endothelial dysfunction, tissue factor pathway inhibitor.

\section{Introduction}

The vascular endothelium is a large paracrine, autocrine and endocrine organ that plays an important role in vascular tone, thrombogenesis and inflammation. Endothelium regulates these systems by producing some mediators; vasoconstrictor and vasodilator factors such as nitric oxide (NO), and also some others regulating platelet activity, clotting cascade and fibrinolysis (1-4). Vasomotor disturbances, abnormal coagulation and fibrinolysis can be seen in endothelial dysfunction (ED) due to impairment of these mediator balances $(3,5-6)$. Under chronic inflammatory process, endothelium loses its ability to protect the vascular system and it leads to atherosclerosis. Decreasing NO activity in vascular system has a central role in endothelial dysfunction dependent vascular atherosclerosis. In addition to this, vascular endothelium is the production site of some pro- and anti-coagulation factors (2-3). In case of ED, disbalance of this ratio in favor of pro-thrombotic properties results in thrombosis. Tissue factor pathway inhibitor (TFPI), which is one of these factors, has an important role in clot-

${ }^{1}$ Istanbul Bilim University, Faculty of Medicine, Department of Cardiology, Istanbul, Turkey, ${ }^{2}$ Sisli Florence Nightingale Hospital, Department of Cardiology, Istanbul, Turkey, ${ }^{3}$ Yildiz Technical University, Department of Biochemistry, Istanbul, Turkey, and ${ }^{4}$ Sisli Florence Nightingale Hospital, Department of Biochemistry, Istanbul, Turkey

Address for correspondence: Kahraman S, MD, Istanbul Bilim University, Faculty of Medicine, Department of Cardiology, Istanbul, Turkey, Bahcelievler Mah. Çalislar Cad. Ressam Namik Ismail Sok. No: 20 D: 14 Bahcelievler/Istanbul 34180

Phone: +90.505.3825921, Fax: +90.212.4719494 ting cascade and thrombosis. Tissue factor (TF) is an endothelium cell surface glycoprotein, which is not normally present on the surface of endothelium and does not support coagulation (7). If it contacts the coagulation factor VII, TF and FVII complex initiates coagulation (8). TFPI is produced by endothelium and it is related to endothelial dysfunction as well (9). TFPI inhibits factor VIITF complex, which starts the clotting cascade (10). TFPI activity is related to atherosclerotic process and coronary artery disease (CAD) (11-15) (Figs 1-3).

Carotid artery changes due to atherosclerosis are related to increased cardiovascular morbidity and mortality (16). Carotid intima media thickness (CIMT) is of importance for atherosclerotic process and is used to evaluate future cardiovascular events and mortality (17-18). The previous studies showed that there was a strong relationship between ED and atherosclerosis (1920). Some noninvasive tests, which are endothelium dependent flow-mediated dilatation (FMD) and endothelium independent nitroglycerin-mediated dilatation (NMD) in the brachial artery (BA), are used to evaluate endothelial function (21-24). In our study, we aimed to associate CAD presence and severity with endothelial dysfunction, carotid intima media thickness and TFPI as an endothelial derived factor.

\section{Methods}

\section{Study design and population}

Eighty patients were included in this study between January 2010 - January 2013 with suspected CAD owing to typical chest pain or positive noninvasive cardiovascular stress testing, who 


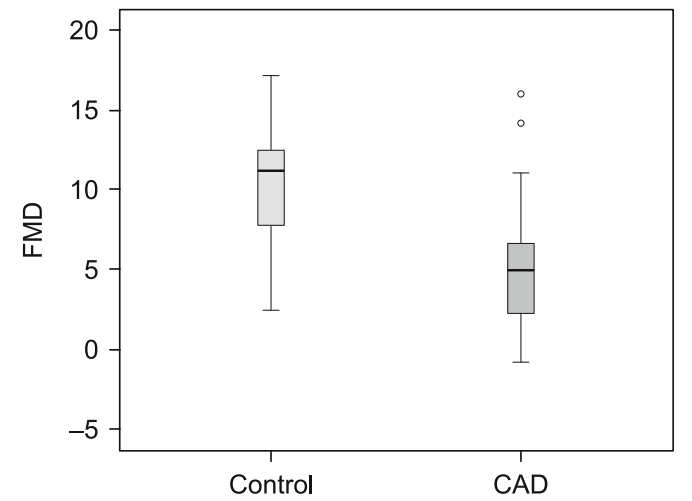

Fig. 1. Endothelial dependent flow mediated vasodilatory response in the CAD and control groups. (CAD - coronary artery disease, FMD - flow mediated vasodilatory response).

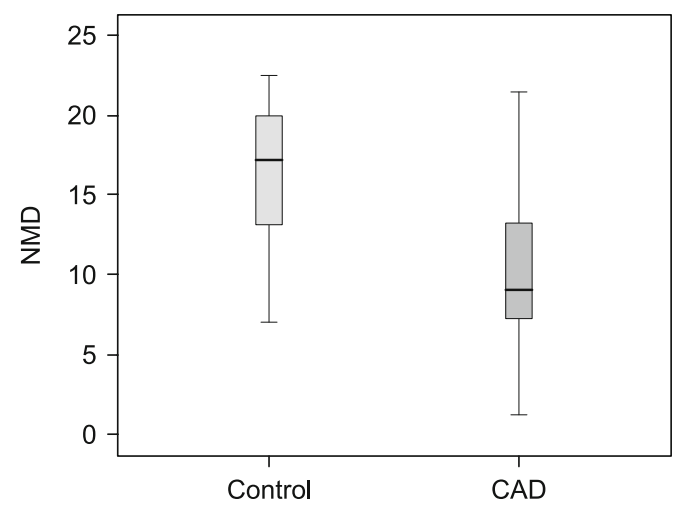

Fig. 2. Endothelial independent nitroglycerin-mediated vasodilatory response in the $\mathrm{CAD}$ and control groups. (CAD - coronary artery disease, NMD - nitroglycerin-mediated vasodilatory response).

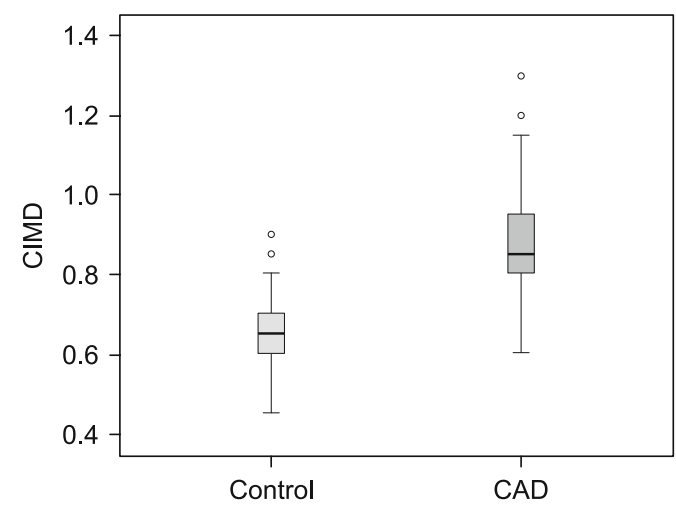

Fig. 3. Carotid intima media thickness in the $\mathrm{CAD}$ and control groups. (CAD - coronary artery disease, CIMT - Carotid intima media thickness).

underwent cardiac catheterization. Patients with acute coronary syndrome, history of coronary angioplasty or coronary artery bypass surgery, chronic renal failure, chronic hepatic failure, rheumatological disorder, history of malignant disease, usage of antithrombotic or anticoagulant treatment were excluded.
The study protocol was approved by local ethics committee and a written informed consent was obtained from all subjects.

\section{Study protocol}

The study was designed as a prospective observational study. Basic demographic data of the enrolled patients included age, gender, body mass index (BMI), glomerular filtration rate (GFR), presence of traditional major cardiovascular risk factors (hypertension (HT), diabetes mellitus (DM), dyslipidemia, family history of premature cardiovascular disease (CVD), and current smoking) and a usage of cardiovascular treatment. Endothelial dysfunction was evaluated before coronary angiography via left brachial artery using brachial artery Doppler ultrasonography (USG) in two different methods; FMD and NMD. CIMT was measured by using carotid artery Doppler USG. All patients' TFPI levels were analyzed. Coronary angiography was performed, and presence and severity of atherosclerosis was evaluated by using Gensini scoring system (GSS) (25).

\section{Statistical analysis}

Data were expressed as the "mean (standard deviation; SD)", "n (\%)" and "median (minimum-maximum)" values, where appropriate. Fisher's exact test and Pearson chi-square analysis was performed for categorical variables. Fitness to normal distribution was analyzed with the Kolmogorov-Simirnov test. Mann-Whitney $\mathrm{U}$ test was used for comparing quantitative variables with abnormal distribution, while Student t-test was used for comparing the means between two groups with normal distribution. Spearman correlation test was performed for correlations between ordinal variables or continuous variables with abnormal distribution. Simple linear regression analyses were applied for CIMT, FMD and NMD to assess the association with Gensini. Multiple logistic regression analysis was used for predicting presence of CAD. Three separate models were conducted for CIMT, FMD and NMD adjusting for age, smoking status and gender. Statistical analysis was made using the computer software Statistical Package for Social Sciences (IBM SPSS Statistics for Windows, version 21.0. released 2012, IBM Corp., Armonk, New York, USA). The p value $<0.05$ was considered statistically significant.

\section{Results}

Clinical and demographic characteristics of the CAD and the control groups are presented in Table 1. In these two groups, there were 50 subjects having CAD and 30 of them had normal coronary arteries. The number of male patients and nonsmokers in the CAD $(+)$ group and the mean age of this group were significantly higher.

Endothelial dependent and independent vasodilatory responses and CIMT were compared between the CAD (+) and control groups in Table 2.

TFPI was a statistically significant determinant between the two groups with an increased level in CAD $(+)$ group $(84.9 \pm 19.3$ vs $70.2 \pm 14.7, \mathrm{p}=0.001)$ (Tab. 3 ).

For patients with CAD, simple linear regression analyses were performed for CIMT, FMD and NMD to predict GSS. These analy- 
Tab. 1. Clinical and demographic characteristics.

\begin{tabular}{|c|c|c|c|}
\hline & Control $(n=30)$ & $\mathrm{CAD}(\mathrm{n}=50)$ & $\mathrm{p}$ \\
\hline Gender (male), $\mathrm{n}(\%)^{\mathrm{a}}$ & $12(40)$ & $33(66)$ & $0.023 *$ \\
\hline $\mathrm{Age}^{\mathrm{b}}$ & $53.7 \pm 9.1$ & $61.8 \pm 7.2$ & $0.001 * * *$ \\
\hline $\mathrm{BMI}^{\mathrm{c}}\left(\mathrm{kg} / \mathrm{m}^{2}\right)$ & $27(22-40)$ & $28(21.2-43)$ & 0.823 \\
\hline $\mathrm{HT}, \mathrm{n}(\%)^{\mathrm{a}}$ & $16(53.3)$ & $31(62)$ & 0.446 \\
\hline Smoking, $\mathrm{n}(\%)^{\mathrm{a}}$ & $3(10)$ & $17(34)$ & $0.016^{*}$ \\
\hline $\mathrm{DM}, \mathrm{n}(\%)^{\mathrm{a}}$ & $6(20)$ & $16(32)$ & 0.245 \\
\hline $\mathrm{TC}^{\mathrm{b}}(\mathrm{mg} / \mathrm{dl})$ & $216 \pm 34.1$ & $217.6 \pm 42$ & 0.854 \\
\hline $\mathrm{HDL}^{\mathrm{c}}(\mathrm{mg} / \mathrm{dl})$ & $44(29-104)$ & $45(25-69)$ & 0.598 \\
\hline nonHDL ${ }^{\mathrm{b}}(\mathrm{mg} / \mathrm{dl})$ & $167.7 \pm 38$ & $171.3 \pm 40.5$ & 0.693 \\
\hline $\mathrm{LDL}^{\mathrm{b}}(\mathrm{mg} / \mathrm{dl})$ & $137.6 \pm 29.4$ & $142.6 \pm 35.8$ & 0.522 \\
\hline $\mathrm{TG}^{\mathrm{c}}(\mathrm{mg} / \mathrm{dl})$ & $149.5(63-348)$ & $150(45-313)$ & 0.839 \\
\hline $\mathrm{GFR}^{\mathrm{b}}(\mathrm{ml} / \mathrm{min})$ & $86.1 \pm 20.5$ & $83.5 \pm 17.5$ & 0.552 \\
\hline $\mathrm{Hgb}^{\mathrm{b}}(\mathrm{g} / \mathrm{dl})$ & $13.3 \pm 1.6$ & $13.4 \pm 1.9$ & 0.836 \\
\hline ACEI, $n(\%)^{\mathrm{a}}$ & $4(13.3)$ & $10(20)$ & 0.447 \\
\hline $\mathrm{ARB}, \mathrm{n}(\%)^{\mathrm{a}}$ & $3(10)$ & $10(20)$ & 0.351 \\
\hline Betabloker, $\mathrm{n}(\%)^{\mathrm{a}}$ & $6(20)$ & $14(28)$ & 0.424 \\
\hline $\mathrm{CCB}, \mathrm{n}(\%)^{\mathrm{a}}$ & $1(3.3)$ & $4(8)$ & 0.645 \\
\hline Nitroglycerin, $n(\%)^{\mathrm{a}}$ & $0(0)$ & $4(8)$ & 0.291 \\
\hline Insulin, $\mathrm{n}(\%)^{\mathrm{a}}$ & $0(0)$ & $4(8)$ & 0.291 \\
\hline $\mathrm{OAD}, \mathrm{n}(\%)^{\mathrm{a}}$ & $5(16.7)$ & $6(12)$ & 0.739 \\
\hline \multicolumn{4}{|c|}{$\begin{array}{l}{ }^{* * *} \mathrm{p}<0.001,{ }^{\mathrm{a}} \text { Chi-square test, }{ }^{\mathrm{b}} \text { Student's } \mathrm{t} \text { test, }{ }^{\mathrm{c}} \mathrm{Mann}-\mathrm{Whitney}-\mathrm{U} \text { test, ACEI - } \\
\text { angiotensin converting enzyme inhibitor, ARB - angiotensin receptor blocker, BMI } \\
\text { - body mass index, CAD - coronary artery disease, CCB }- \text { calcium channel blocker, } \\
\text { DM - diabetes mellitus, GFR - glomerular filtration rate, HDL - high density lipo- } \\
\text { protein, Hgb - hemoglobin, HT - hypertension, LDL - low density lipoprotein, OAD } \\
- \text { oral antidiabetic agent, TC - total cholesterol, TG - triglyceride }\end{array}$} \\
\hline
\end{tabular}

Tab. 2. CIMT, NMD and FMD values of CAD and control groups.

\begin{tabular}{lccc}
\hline & Control & CAD & $\mathrm{p}$ \\
\hline $\mathrm{CIMT}^{\mathrm{a}}(\mathrm{cm})$ & $0.64 \pm 0.1$ & $0.86 \pm 0.1$ & $0.001 * * *$ \\
$\mathrm{FMD}^{\mathrm{b}}(\%)$ & $11.2(2.4-17.2)$ & $4.9(0.8-16)$ & $0.001 * * *$ \\
$\mathrm{NMD}^{\mathrm{b}}(\%)$ & $17.3(7-22.5)$ & $9.1(1.2-21.5)$ & $0.001 * * *$ \\
\hline$* * * \mathrm{p}<0.001,{ }^{a}$ Stu
\end{tabular}

***p $<0.001$, aStudent's $t$ test, ${ }^{\mathrm{b}}$ Mann-Whitney - U test , CAD - coronary artery disease, CIMT - carotid intima media thickness, FMD - flow-mediated dilatation, NMD - nitroglycerin-mediated dilatation

Tab. 3. TFPI levels of CAD and control groups.

\begin{tabular}{lccc}
\hline & Control & CAD & $p$ \\
\hline $\mathrm{TFPI}^{\mathrm{a}}(\mathrm{mg} / \mathrm{dl})$ & $70.2 \pm 14.7$ & $84.9 \pm 19.3$ & 0.001 \\
\hline aStudent's test & $\mathrm{CAD}$ & - coronary artery disease & TFPI - tissue factor pathway inhibitor
\end{tabular}

ses revealed that CIMT $(\beta=0.282 ; p=0.047), \operatorname{FMD}(\beta=-0.581$; $\mathrm{p}<0.001)$ and NMD $(\beta=-0.593 ; \mathrm{p}<0.001)$ were independent risk factors for GSS. There was a positive correlation between CIMT and Gensini ( $r=0.34, \mathrm{p}=0.014)$ (Fig. 4). There was a strong negative correlation between Gensini and FMD and NMD with statistical significant (FMD: $r=-0.715, \mathrm{p}<0.001$ ) (Fig. 5); NMD: $\mathrm{r}=-0.718, \mathrm{p}<0.001$ ) (Fig. 6).

Three regression models were conducted to evaluate the association between CIMT, FMD, NMD with CAD adjusting for gender, age and smoking status. The patient's smoking status was not significant in three models. Model 1 showed that CIMT was positively associated with CAD $(p=0.002)$. TFPI was significantly associated with CAD in Model 1, 2 and $3\left(\mathrm{p}_{1}=0.017 ; \mathrm{p}_{2}=0.036\right.$; $\mathrm{p}_{3}=0.031$ respectively). In model 1 and 3 , both gender (male) and age were significantly related with CAD. In Model 2, the association between gender and CAD was not statistically significant, but

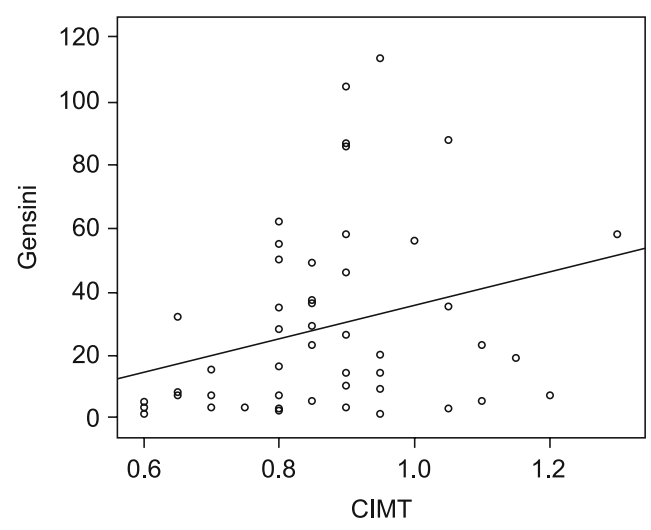

Fig. 4. The relationship between CIMT and Gensini (CIMT - Carotid intima media thickness).

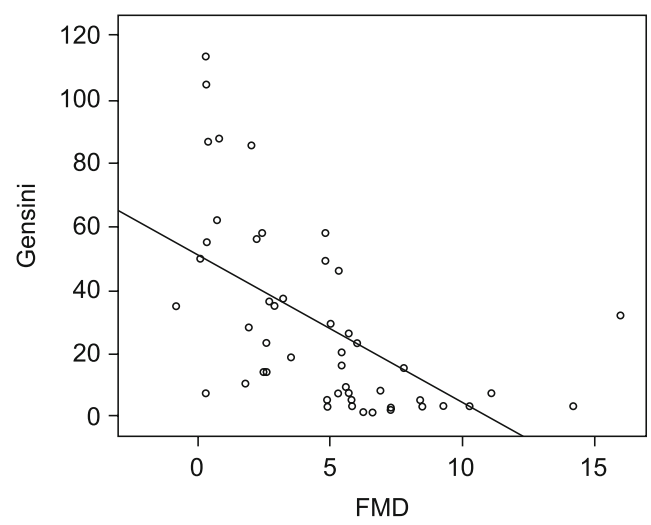

Fig. 5. The relationship between FMD and Gensini (FMD - flow mediated vasodilatory response).

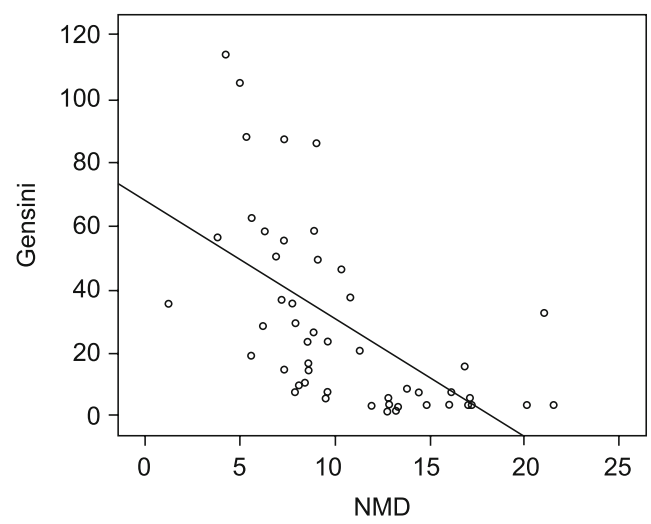

Fig. 6. The relationship between NMD and Gensini (NMD - nitroglycerin-mediated vasodilatory response).

the association between age and CAD remained significant $(\mathrm{p}=$ 0.024). In Model 2 and 3, it was found that both FMD and NMD values of patients were negatively related to $\mathrm{CAD}\left(\mathrm{p}_{\text {find }}=0.004\right.$; $\left.\mathrm{p}_{\mathrm{nmd}}=0.009\right)($ Tab. 4). 
Tab. 4. Logistic regression analysis giving information about the independent risk factors for CAD.

\begin{tabular}{|c|c|c|c|c|c|c|}
\hline Model I & B & S.E. & Wald & $\mathrm{p}$ & OR & $95 \% \mathrm{CI}$ \\
\hline Age & 0.119 & 0.057 & 4.423 & $0.035 *$ & 1.126 & $1.008-1.259$ \\
\hline Gender(male) & 2.163 & 0.878 & 6.069 & $0.014 *$ & 8.701 & $1.556-48.653$ \\
\hline Smoking & -0.638 & 1.002 & 0.405 & 0.524 & 0.528 & $0.074-3.776$ \\
\hline TFPI & 0.058 & 0.024 & 5.745 & $0.017^{*}$ & 1.059 & $1.011-1.110$ \\
\hline CIMT & 1.196 & 0.384 & 9.694 & $0.002 * *$ & 3.306 & $1.557-7.017$ \\
\hline Model II & B & S.E. & Wald & $\mathrm{p}$ & OR & $95 \% \mathrm{CI}$ \\
\hline Age & 0.121 & 0.054 & 5.073 & $0.024 *$ & 1.129 & $1.016-1.255$ \\
\hline Gender(male) & 1.526 & 0.870 & 3.076 & 0.079 & 4.598 & $0.836-25.289$ \\
\hline Smoking & 0.102 & 0.939 & 0.012 & 0.914 & 1.107 & $0.176-6.972$ \\
\hline TFPI & 0.053 & 0.025 & 4.400 & $0.036^{*}$ & 1.055 & $1.003-1.108$ \\
\hline FMD & -0.299 & 0.104 & 8.282 & $0.004 * *$ & 0.742 & $0.605-0.909$ \\
\hline Model III & B & S.E. & Wald & $\mathrm{p}$ & OR & $95 \% \mathrm{CI}$ \\
\hline Age & 0.144 & 0.054 & 7.097 & $0.008^{*}$ & 1.155 & $1.039-1.284$ \\
\hline Gender(male) & 1.656 & 0.843 & 3.860 & $0.049 *$ & 5.237 & $1.004-27.313$ \\
\hline Smoking & 0.013 & 0.907 & 0.000 & 0.988 & 1.013 & $0.171-5.994$ \\
\hline TFPI & 0.053 & 0.024 & 4.661 & $0.031 *$ & 1.054 & $1.005-1.106$ \\
\hline NMD & -0.200 & 0.076 & 6.860 & $0.009^{*}$ & 0.819 & $0.705-0.951$ \\
\hline
\end{tabular}

${ }^{*} \mathrm{p}<0.05 ;{ }^{*} \mathrm{p}<0.01 ; \mathrm{CI}$ - confidence interval; OR - odds ratio, CIMT - carotid intima media thickness, FMD - flow-mediated dilatation, NMD - nitroglycerin-mediated dilatation, TFPI - tissue factor pathway inhibitor

\section{Discussion}

In the present study, we investigated the relationship of TFPI levels and endothelial dysfunction with coronary artery atherosclerosis. Atherosclerosis is the most common cause of morbidity and mortality all over the world (27). This inflammatory process can be affected and progressed by ED. There is a strong correlation between ED and atherosclerosis. Atherosclerotic lesions can be progressed rapidly in the presence of ED (28). First human study of ED by Ludmer et al indicated the evidence of impaired endothelium dependent dilatation in the presence of atherosclerosis (29). According to this study, in the mild CAD patients, there was a paradoxical construction in the arteries and it was indicated that ED could be present in the early stage of atherosclerosis. The impairment of endothelial function also predicts cardiovascular clinical outcomes. Cardiovascular events, including percutaneous and surgical revascularization occurred more often in patients with impaired FMD (30). In our study, there was a strong relationship between ED and coronary atherosclerosis. Both endothelial dependent flow mediated, and independent nitroglycerin mediated vasodilatory responses were significantly decreased in the CAD $(+)$ group compared to the control group $(\mathrm{p}<0.001)$.

Risk factors of coronary atherosclerosis also affect endothelial functions. In the Framingham study, there was a relationship between coronary risk factors and endothelial function (31). It was indicated that ED was related to age, systolic blood pressure, BMI, lipid lowering medication, and smoking and inversely correlated to female gender, heart rate and prior walk test. There is a strong relationship between endothelial function and coronary risk factors with an increased prevalence of endothelial dysfunction in the female gender and advanced age (32-34). In our study, it was revealed that the number of male patients and the mean age of the group were higher in CAD (+) than in the control group, and also the regression analysis indicated that ED was found to be correlated to male gender and advanced age. We did not find any relationship between HT, HL, DM, BMI and ED and CAD. This result maybe explained that almost all of the participants were under an optimal medical therapy for HT, HL and DM.

It is well- known that smoking is one of the most important risk factor for atherosclerosis and smoking causes ED as the result of impairment of endothelial dependent dilatation $(35,36)$. Additionally, FMD was increased in smokers that did not smoke within six hours before testing than in those who did (31). While the number of smokers was higher in the CAD $(+)$ group in our study, the regression analysis revealed that there was no association between smoking and ED in CAD patients. It could be the result of smoking withheld for at least 12 hours before our study.

The presence and severity of coronary atherosclerosis is of importance for prognosis and treatment. In the previous studies, brachial and coronary artery endothelial functions were found to be related (16). In addition, CIMT, which is an indicator of ED, is regarded as a manifestation of atherosclerosis $(37,38)$, and is related to an increased cardiovascular morbidity and mortality (16). CIMT is of importance for atherosclerotic process and is used to evaluate future cardiovascular events and mortality (17-18). A strong correlation between ED and the number of diseased coronary vessels and higher cardiovascular event rates were also observed (39-40). We found that an impairment of endothelial function and increased CIMT were observed with a higher incidence in CAD $(+)$ patients. Besides, a strong correlation between ED, which is evaluated with NMD, FMD and CIMT measurements, and coronary atherosclerotic burden, which was evaluated by using GSS, was found in our study.

Healthy endothelium regulates the balance between pro- and anti-inflammatory substances and pro- and anti-coagulant factors. Normally, TF is not present on the surface of the endothelial cells and endothelium does not support coagulation. Chronic endothelial activation results in endothelial dysfunction. It causes an impairment of vasodilatory response, increased thrombogenesis and inflammation (41). ED can be assessed by vasodilatory response 
(FMD or NMD) and the measurement of endothelial markers (42). TFPI is one of the most important endothelial markers and is associated with endothelial dysfunction and inflammation. It is the main inhibitor of TF-mediated coagulation and co-localizes with TF in atherosclerotic plaques. It was shown that TFPI shows a positive correlation with ED (9) and TFPI levels increases during ED (43). In the light of foregoing data, increased levels of TFPI are associated with FMD and atherosclerosis $(9,44)$. The association between increased TFPI levels and asymptomatic or overt atherosclerosis has been studied in several studies. The association between TFPI levels and subclinical atherosclerosis was found to be significant (45). On the other hand, there is a relationship between increased TFPI levels and adverse cardiovascular events. Higher TFPI level was associated with future cardiovascular events including cardiac death, myocardial infarction and a need for revascularization (46) and increased TFPI level was observed in patients with cardiovascular death (47). In our study, an increased TFPI level was shown in patients with CAD. It showed the relationship between TFPI level and atherosclerosis. In addition to this, CAD $(+)$ patients having increased TFPI levels also presented with ED with impairment of FMD and NMD. The association between increased TFPI levels and ED, was revealed. Besides, TFPI activity was associated with subclinical cerebrovascular disease (48) and found to be an independent predictor of CIMT $(49,50)$. In our study, CAD $(+)$ patients had both increased TFPI levels and CIMT. It was not surprising that under inflammatory process, endothelial dysfunction resulted in increased TFPI levels and also caused an increased CIMT as a manifestation of atherosclerosis.

\section{Learning points}

It was demonstrated in our study that TFPI had a strong effect on atherosclerotic process including coronary atherosclerosis. Non-coronary atherosclerosis detecting by CIMT, FMD and NMD was also related to coronary atherosclerotic process and burden.

\section{Limitations of the Study}

In our study, the major limitation was the small number of subjects in the CAD (+) group. While ultrasonographic evaluation of brachial artery is the accepted method for assessment ED, the role of this method in subclinical disease is not known well.

\section{Conclusion}

In the present study, we demonstrated that coronary atherosclerotic burden was associated with impairment of endothelial function as well as increased CIMT and TFPI activity. In addition to these, increased CIMT measurements and decreased FMD and NMD values had a positive correlation to the extend and severity of coronary artery disease. Consequently, we suggested the TFPI as a surrogate marker of coronary atherosclerotic disease as well as ED and increased CIMT.

\section{References}

1. Libby P, Ridker PM, Maseri A. Inflammation and atherosclerosis. Circulation 2002; 105: 1135-1143.

2. Vane JR, Anggård EE, Botting RM. Regulatory functions of the vascular endothelium. N Engl J Med 1990; 323: 27-36.

3. Lüscher TF, Vanhoutte PM. The endothelium: modulator of cardiovascular function. Boca Raton, Fla: CRC Press, 1990: 1-215.

4. Furchgott RF, Zawadzki JV. The obligatory role of endothelial cells in the relaxation of arterial smooth muscle by acetylcholine. Nature 1980; 288: $373-376$.

5. Drexler H. Endothelial dysfunction: clinical implications. Prog Cardiovasc Dis 1997; 39: 287-324.

6. Kinlay S, Libby P, Ganz P. Endothelial function and coronary artery disease. Curr Opin Lipidol 2001; 12: 383-389.

7. Wilcox JN, Smith KM, Schwartz SM, Gordon D. Localization of tissue factor in the normal vessel wall and in the atherosclerotic plaque. Proc Natl Acad Sci U S A 1989; 86: 2839-2843.

8. Bach RR. Initiation of coagulation by tissue factor. CRC Crit Rev Biochem 1988; 23: 339-368.

9. Mitchell CT, Kamineni A, Palmas W, Cushman M. Tissue factor pathway inhibitor, vascular risk factors and subclinical atherosclerosis: The Multi-Ethnic Study of Atherosclerosis. Atherosclerosis 2009; 207: 277-283.

10. Sere KM, Hackeng TM. Basicmechanisms of hemostasis. Semin VascMed 2003; 3: 3-12.

11. Falciani M, Gori AM, Fedi S et al. Elevated tissue factor and tissue factor pathway inhibitor circulating levels in ischaemic heart disease patients. Thromb Haemost 1998; 79: 495-499.

12. Habib SS. Plasma tissue factor pathway inhibitor levels in angiographically defined coronary artery disease among saudis. Oman Med J 2013; 28: 191-194.

13. Al-Nozha MM, Abdel-Gader AG, Arafah MR et al. Tissue factor pathway inhibitor, natural coagulation inhibitors and hemostatic activation markers in patients with acute coronary syndromes. Saudi Med J 2005; 26: $937-942$.

14. Hong J, Liu R, Chen $L$ et al. Conditional knockout of tissue factor pathway inhibitor 2 in vascular endothelial cells accelerates atherosclerotic plaque development in mice. Thrombo Res 2016; 137: 148-156.

15. Chen D, Xia M, Hayford C et al. Expression of human tissue factor pathway inhibitor on vascular smooth muscle cells inhibits secretion of macrophage migration inhibitory factor and attenuates atherosclerosis in ApoE-/- mice. Circulation 2015; 131: 1350-1360.

16. Anderson TJ, Uehata A, Gerhard MD et al. Close relation of endothelial function in human coronary and peripheral circulations. J Am Coll Cardiol 1995; 26: 1235-1241.

17. Greenland P, Smith SC, Grundy SM. Improving coronary heart disease risk assessment in asymptomatic people: role of traditional risk factors and noninvasive cardiovascular tests. Circulation 2001; 104: $1863-1867$.

18. O’Leary DH, Polak JF, Kronmal RA, Manolio TA, Burke GL, Wolfson SK Jr. Carotid-artery intima and media thickness as a risk factor for myocardial infarction and stroke in older adults. Cardiovascular Health Study Collaborative Research Group. N Engl J Med 1999; 340: 14-22. 
19. Heiss C, Lauer T, Dejam A et al. Plasma nitroso compounds are decreased in patients with endothelial dysfunction. J Am Coll Cardiol 2006; 47: 573-579.

20. Cox DA, Vita JA, Treasure CB et al. Atherosclerosis impairs flowmediated dilation of coronary arteries in humans. Circulation 1989; 80; $458-465$.

21. Laurent S, Lacolley P, Brunel P, Laloux B, Pannier B, Safar M. Flow-dependent vasodilation of brachial artery in essential hypertension. Am J Physiol 1990; 258: 1004-1011.

22. Anderson EA, Mark AL. Flow-mediated and reflex changes in large peripheral artery tone in humans. Circulation 1989; 79: 93-100.

23. Celermajer DS, Sorensen KE, Gooch VM et al. Non-invasive detection of endothelial dysfunction in children and adults at risk of atherosclerosis. Lancet 1992; 340: 1111-1115.

24. Sorensen KE, Celermajer DS, Spiegelhalter DJ et al. Non-invasive measurement of human endothelium dependent arterial. Br Heart J 1995; 74: $247-253$.

25. Gensini GG. A more meaningful scoring system for determining the severity of coronary heart disease. Am J Cardiol 1983; 51: 606.

26. Corretti MC, Anderson TJ, Benjamin EJ et al. Guidelines for the ultrasound assessment of endothelial-dependent flowmediated vasodilation of the brachial artery: a report of the International Brachial Artery Reactivity Task Force. J Am Coll Cardiol 2002; 39: 257-265.

27. Mathers CD, Loncar D. Projections of global mortality and burden of disease from 2002 to 2030. PLoS Med 2006; 3: 442.

28. Vogel RA. Cholesterol lowering and endothelial function. Am J Med 1999; 107: 479-487.

29. Ludmer PL, Selwyn AP, Shook TL et al. Paradoxical vasoconstriction induced by acetylcholine in atherosclerotic coronary arteries. N Engl J Med 1986; 315: 1046-1051.

30. Neunteufl T, Heher S, Katzenschlager R et al. Late prognostic value of flow-mediated dilation in the brachial artery of patients with chest pain. Am J Cardiol 2000; 86: 207-210.

31. Benjamin EJ, Larson MG, Keyes MJ et al. Clinical correlates and heritability of flowmediated dilation in the community: The Framingham Heart Study. Circulation 2004; 109: 613-619.

32. Uehata A, Lieberman EH, Meredith IT et al. Non-invasive assessment of flow-mediated vasodilation in brachial arteries: diminished response in young males compared to females. Circulation 1992; 86: $1-620$.

33. Jensen-Urstad K, Johansson J. Gender difference in age-related changes in vascular function. J Intern Med 2001; 250: 29-36.

34. Kirma C, Akcakoyun M, Esen AM et al. Relationship between endothelial function and coronary risk factors in patients with stable coronary artery disease. Circ J 2007; 71: 698-702.

35. Esen AM, Barutcu I, Acar M et al. Effect of smoking on endothelial function and wall thickness of brachial artery. Circ J 2004; 68: 1123-1126.
36. Raij L, DeMaster EG, Jaimes EA. Cigarette smoke-induced endothelium dysfunction: role of superoxide anion. J Hypertens 2001; 19: 891-897.

37. Salonen JT, Salonen R. Ultrasonographically assessed carotid morphology and the risk of coronary heart disease. Arterioscler Thromb 1991; 11: $1245-1249$.

38. Liu L, Lu ZY, Lei MX, Wu J, Huang Z. Effect of plasma glucose on the vascular endothelial function and analysis of relevant factors. Zhong Nan Da Xue Xue Bao Yi Xue Ban 2006; 31: 830-833.

39. Neunteufl T, Katzenschlager R, Hassan A et al. Systemic endothelial dysfunction is related to the extent and severity of coronary artery disease. Atherosclerosis 1997; 129: 111-118.

40. Schachinger V, Britten MB, Zeiher AM. Prognostic impact of coronary vasodilator dysfunction on adverse long-term outcome of coronary heart disease. Circulation 2000; 101: 1899-1906.

41. Bonetti PO, Lerman LO, Lerman A. Endothelial dysfunction: a marker of atherosclerotic risk. Arterioscler Thromb Vasc Biol 2003; 23 : $168-175$.

42. Deanfield JE, Halcox JP, Rabelink TJ. Endothelial function and dysfunction: testing and clinical relevance. Circulation 2007; 115: 1285-1295.

43. Crawley J, Lupu F, Westmuckett AD, Severs NJ, Kakkar VV, Lupu C. Expression, localization, and activity of tissue factor pathway inhibitor in normal and atherosclerotic human vessels. Arterioscler Thromb Vasc Biol 2000; 20: 1362-1373.

44. Furomoto T, Fujii S, Saito N, Mikami T, Kitabatake A. Relationships between brachial artery flow mediated dilation and carotid artery intima-media thickness in patients with suspected coronary artery disease. Jpn Heart J 2002; 43: 117-125.

45. Novo G, Caplice N, Tantillo R, Bonura F, Simari R, Novo S. TFPI antigen and activity levels in patients with asymptomatic atherosclerosis and target organ acute and chronic complications. Int Angiol 2005; 24 : 366-371.

46. Soejima $H$, Ogawa $H$, Yasue $H$ et al. Heightened tissue factor associated with tissue factor pathway inhibitor and prognosis in patients with unstable angina. Circulation 1999; 99: 2908-2913.

47. Morange PE, Blankenberg S, Alessi MC et al. Prognostic value of plasma tissue factor and tissue factor pathway inhibitor for cardiovascular death in patients with coronary artery disease: the AtheroGene study. J Thromb Haemost 2007; 5: 475-482.

48. Sakkinen PA, Cushman M, Psaty BM et al. Correlates of antithrombin, protein $\mathrm{C}$, protein $\mathrm{S}$, and TFPI in a healthy elderly cohort. Thromb Haemost 1998; 80: 134-139.

49. Sebestjen M, Zegura B, Videcnik V, Keber I. Determinants of endothelial dysfunction and carotid intima-media thickness in combined hyperlipidemia. Coron Artery Dis 2005; 16: 175-180.

50. Sakata T, Mannami T, Baba S et al. Potential of free-form TFPI and PAI-1 to be useful markers of early atherosclerosis in a Japanese general population (the Suita Study): association with the intimal-medial thickness of carotid arteries. Atherosclerosis 2004; 176: 355-360. 